\title{
Late-onset riboflavin-responsive multiple acyl-CoA dehydrogenase deficiency (MADD): case reports and epidemiology of ETFDH gene mutations
}

Wei Chen ${ }^{1+}$, Youqiao Zhang ${ }^{1 \dagger}$, Yifeng $\mathrm{Ni}^{1}$, Shaoyu Cai ${ }^{1}$, Xin Zheng ${ }^{1}$, Frank L. Mastaglia ${ }^{2}$ and Jingshan $\mathrm{Wu}^{1,3^{*}}$ (1)

\begin{abstract}
Background: Multiple acyl-CoA dehydrogenase deficiency (MADD) is a riboflavin-responsive lipid-storage myopathy caused by mutations in the EFTA, EFTB or ETFDH genes. We report a Chinese family of Southern Min origin with two affected siblings with late-onset riboflavin-responsive MADD due to a homozygous c.250G > A EFTDH mutation and review the genetic epidemiology of the c.250G > A mutation.

Case presentation: Both siblings presented with exercise-induced myalgia, progressive proximal muscle weakness and high levels of serum muscle enzymes and were initially diagnosed as polymyositis after a muscle biopsy. A repeat biopsy in one sibling subsequently showed features of lipid storage myopathy and genetic analysis identified a homozygous mutation (c.250G > A) in the ETFDH gene in both siblings and carriage of the same mutation by both parents. Glucocorticoid therapy led to improvement in muscle enzyme levels, but little change in muscle symptoms, and only after treatment with riboflavin was there marked improvement in exercise tolerance and muscle strength. The frequency and geographic distribution of the c.250G > A mutation were determined from a literature search for all previously reported cases of MADD with documented mutations. Our study found the c.250G > A mutation is the most common EFTDH mutation in riboflavin-responsive MADD (RR-MADD) and is most prevalent in China and South-East Asia where its epidemiology correlates with the distribution and migration patterns of the southern Min population in Southern China and neighbouring countries.

Conclusions: Mutations in ETFDH should be screened for in individuals with lipid-storage myopathy to identify patients who are responsive to riboflavin. The c.250G > A mutation should be suspected particularly in individuals of southern Min Chinese background.
\end{abstract}

Keywords: Late-onset multiple acyl-CoA dehydrogenase deficiency, Lipid storage myopathy, ETFDH gene, C.250G > A mutation, Southern min population, Epidemiology

\footnotetext{
* Correspondence: jingshan.wu@uwa.edu.au

tWei Chen and Youqiao Zhang contributed equally to this work.

'Department of Neurology, The Second Affiliated Hospital of Shantou

University Medical College, Shantou, Guangdong, China

${ }^{3}$ Faculty of Health and Medical Sciences, The University of Western Australia,

(M503), 35 Stirling Highway, Perth, Western Australia 6009, Australia

Full list of author information is available at the end of the article
}

(c) The Author(s). 2019 Open Access This article is distributed under the terms of the Creative Commons Attribution 4.0 International License (http://creativecommons.org/licenses/by/4.0/), which permits unrestricted use, distribution, and

reproduction in any medium, provided you give appropriate credit to the original author(s) and the source, provide a link to the Creative Commons license, and indicate if changes were made. The Creative Commons Public Domain Dedication waiver (http://creativecommons.org/publicdomain/zero/1.0/) applies to the data made available in this article, unless otherwise stated. 


\section{Background}

Multiple acyl-CoA dehydrogenase deficiency (MADD) is an autosomal recessive disorder caused by mutation of the electron transfer flavoprotein A (ETFA), electron transfer flavoprotein B (ETFB), or electron transfer flavoprotein dehydrogenase (ETFDH) genes, resulting in dysfunction of mitochondrial electron transfer and lipid storage myopathy (LSM) [1-3]. MADD is classified into a severe early-onset form and a milder late-onset form manifesting in adolescence or adult-life with fluctuating exercise intolerance, myalgia, progressive proximal muscle weakness, and in some cases hypoglycaemia and metabolic acidosis. Most MADD patients improve dramatically after treatment with riboflavin, thus the condition is called riboflavin-responsive MADD (RR-MADD). The late-onset form accounts for about $90 \%$ of cases of LSM in China and is related to ETFDH deficiency [1, 4]. A wide spectrum of different ETFDH mutations has been reported worldwide, of which c.250G > A (p.Ala84Thr) is the most common, being found predominantly in southern China, while c.770A $>$ G (p.Try257Cys) and c.1227A > C (p.Leu409Phe) are more common in northern China [4].

Here we report two brothers with adolescent RRMADD from a southern Min Chinese pedigree who were homozygous for the c.250G > A mutation, and were initially misdiagnosed as having an inflammatory myopathy. We also review the genetic epidemiology of the c.250G > A mutation in China and around the world which is strongly suggestive of a founder effect in the southern Min Chinese population.

\section{Case presentation}

Case 1

The proband was a 19-year-old male with a 3 month history of exercise intolerance, myalgia and muscle weakness which was more severe in the lower limbs. Physical examination found reduced muscle tone and mild weakness of proximal muscles (MRC 4/5). Electromyography revealed myopathic motor unit changes in limb muscles without spontaneous discharges. A presumptive diagnosis of polymyositis was made and he was started on prednisone $1 \mathrm{mg} / \mathrm{kg}$ for 3 weeks, during which the serum creatine kinase (CK) level fell from $911 \mathrm{U} / \mathrm{L}$ to $190 \mathrm{U} / \mathrm{L}$ (normal range 0-174 U/L) and there was slight improvement in muscle weakness, but the myalgia and exercise intolerance persisted. Levels of other biochemical parameters also dropped but still remained above the normal range, including LDH (1624 U/L to $1066 \mathrm{U} / \mathrm{L})$, AST (188 U/L to $76 \mathrm{U} / \mathrm{L})$ and uric acid $(738 \mu \mathrm{mol} / \mathrm{L}$ to $665 \mu \mathrm{mol} / \mathrm{L})$ after treatment with prednisone.

\section{Case 2}

A 13-year-old male, the younger brother of the proband, presented with a 1 year history of progressive muscle weakness and myalgia worse after exercise. Neurological examination found reduced muscle tone and mild proximal weakness in the lower limbs (MMT 4/5). Biochemical tests showed raised serum CK (2165 U/L), CK-MB $(103 \mathrm{ng} / \mathrm{ml})$ and uric acid levels $(709 \mu \mathrm{mol} / \mathrm{L})$. MRI of the lower limbs showed focal areas of increased signal intensity in the gluteal and thigh muscles on short time inversion recovery (STIR) sequences, suggesting a diagnosis of possible polymyositis. A muscle biopsy taken from the right biceps femoris showed only a small focal lymphocytic infiltrate but no other abnormalities. Echocardiography showed mildly reduced ventricular diastolic function. He was commenced on oral prednisone $(1 \mathrm{mg} / \mathrm{kg})$, following which there was a fall in the serum CK (2165 U/L to $612 \mathrm{U} / \mathrm{L})$, CK-MB $(103 \mathrm{ng} / \mathrm{ml}$ to $51 \mathrm{ng} / \mathrm{ml})$ and uric acid level $(709 \mu \mathrm{mol} / \mathrm{L}$ to $415 \mu \mathrm{mol} / \mathrm{L})$, but there was no improvement in his muscle symptoms.

The patient then reported that he had an elder brother (the proband) who had similar symptoms, and that their parents did not have any muscle symptoms and were not consanguineous. A second muscle biopsy from the left quadriceps femoris did not provide any confirmatory evidence of an inflammatory myopathy but revealed prominent cytoplasmic vacuolation of muscle fibres strongly suggestive of a lipid storage myopathy. The patient was then started on riboflavin $(30 \mathrm{mg}$, three times per day) and the prednisone was discontinued. After 3 days of riboflavin therapy there was already considerable improvement in muscle strength and exercise tolerance.

Late-onset MADD was suspected and blood was collected from all family members and sent to MyGenostics for genetic analysis. Sanger sequencing was performed for the ETFA, ETFB and ETFDH genes as well as other neuromuscular disease related genes. This identified a homozygous ETFDH gene mutation of c.250G > A (p.A84T) in exon 3, chr4-159,603,421 (Fig.1a) in both brothers, and a heterozygous mutation in both parents (Fig.1b). No variants were detected in ETFA, ETFB or other genes.

After 1 month of riboflavin treatment there was marked improvement in myalgia and exercise intolerance in both brothers and the MMT scores in proximal limb muscles had improved to $5 / 5$. Both patients have since been able to walk and run freely and the younger brother is now able to participate in school sporting activities. Serum CK levels fell markedly after commencement of riboflavin and have remained normal in both patients over the past year.

\section{Genetic epidemiology of the ETFDH c.250G > A mutation} We ascertained the frequency of reported cases of MADD with confirmed ETFDH mutations through Pubmed and the Wanfang Database in China. In the reviews of 350 late-onset cases of MADD by Grunert in 2014 and 90 cases by $\mathrm{Xi}$ in 2013 [5], 244 individuals had confirmed 
A09_S051305_17C002827_ETFDH-Chr4-159603421_F326-J8_F.ab1
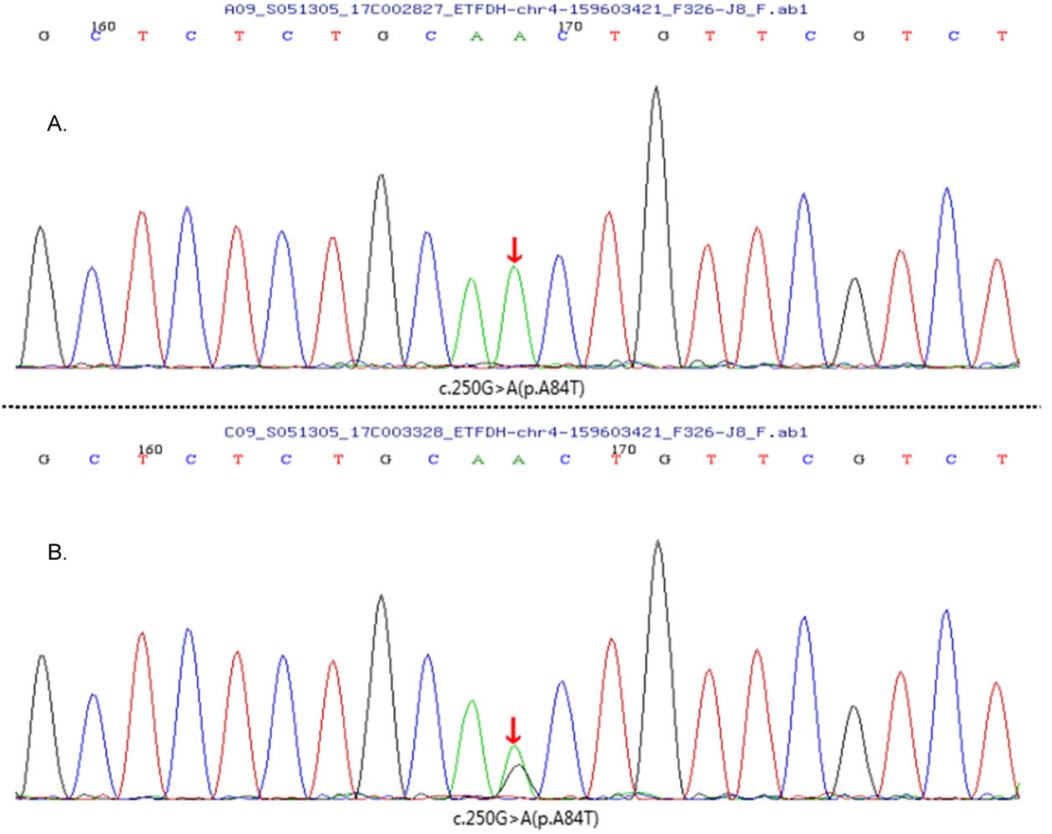

Fig. 1 Sequencing of the electron transfer flavoprotein dehydrogenase gene of the two patients (a) and their parents (b), showed the same missense mutation of c.250G > A (p.A84T) in exon 3, chr4-159,603,421. In patient 1 and patient 2, the mutation was homozygous while in their parents it was heterozygous

EFTDH mutations. A further 137 cases of EFTDH mutation related MADD have since been reported and were added into our study. In total, there are 381 cases of MADD with 113 different EFTDH mutations reported in over 110 studies to date [5-44] (Additional file 1: Table S1). The frequencies of the 6 most common mutations are shown in Table 1. Overall, the c.250G > A mutation is the most common ETFDH mutation, accounting for $28.1 \%$ of reported cases, 59 of which were homozygous (including our cases) and 48 cases had compound heterozygous mutations. The other common mutations were c.770A > G (12.9\%) and c.1227A > C (8.9\%) in Chinese, and c.1130 $\mathrm{T}>\mathrm{C}(6.3 \%)$ in the Turkish population [37].

We further analysed the distribution of the EFTDH mutation cases and the frequency of the c.250G > A allele among all reported EFTDH mutations in different Chinese provinces/regions, South-East Asian countries, and globally. As shown in Fig. 2, the highest frequencies of c.250G > A mutation MADD cases were observed in the Fujian, Guangzhou and Chaoshan regions, and in Taiwan and Hainan islands, all of which have a strong southern Min background. We estimated the approximate net Southern Min population in each province/region in China and neighbouring countries, and the approximate percentage of the population they comprise based on data from the Internet. As showed in Table 2, the percentage of c.250G > A allele is significantly correlated with the distribution of southern Min population in China and surrounding countries (Spearman correlation $p<0.01$ ), suggesting a founder effect of the c.250G > A mutation in this population.

Three cases of MADD with the c.250G > A mutation have been reported in Thailand, where over $10 \%$ of the population is of Chinese descent [7], the majority of them being southern Min people who migrated from the

Table 1 The frequency and ethnic distribution of the 6 most common ETFDH mutations among 381 reported cases of MADD with a proven ETFDH mutation

\begin{tabular}{|c|c|c|c|c|c|}
\hline ETFDH & Homozygous & Heterozygous & Population & Total cases & Percentage \\
\hline c. $250 G>A$ & 59 & 48 & Chinese/Asian & 107 & $28.1 \%$ \\
\hline c. $770 \mathrm{~A}>\mathrm{G}$ & 4 & 45 & Chinese/Asian & 49 & $12.9 \%$ \\
\hline c. $1227 \mathrm{~A}>\mathrm{C}$ & 1 & 33 & Chinese & 34 & $8.9 \%$ \\
\hline C.1130T>C & 24 & 0 & Turkish & 24 & $6.3 \%$ \\
\hline c.389 A > T & 0 & 22 & Chinese & 22 & $5.8 \%$ \\
\hline C. $1367 C>T$ & 4 & 5 & Caucasians/Japanese & 9 & $2.4 \%$ \\
\hline
\end{tabular}


Chaoshan region of China in the last two centuries. The only reported case of MADD with the c.250G > A mutation in Western countries is in France, in an individual of Chinese origin [35]. There have not been any reported cases with the c.250G > A mutation among Koreans [13], Japanese [45] or Caucasians.

\section{Discussion}

We report a Southern Min Chinese family with two siblings carrying the c.250G > A (p.Ala84Thr) mutation in the ETFDH gene who presented with typical features of adolescent-onset riboflavin responsive multiple acyl-CoA dehydrogenase deficiency (MADD) associated lipidstorage myopathy. In addition, Case 2 also had echocardiographic evidence of ventricular diastolic dysfunction and cardiomyopathy, which has been commonly reported in early-onset MADD, but is rare in the lateonset form of the disease [1, 4, 46-49]. As late-onset MADD is a rare disease and the symptoms are nonspecific, it is not uncommon for the diagnosis to be delayed and for the condition to be misdiagnosed, as occurred in the present cases who were initially thought to be suffering from an inflammatory myopathy [4, 46-48]. Although less effective than riboflavin, glucocorticoid therapy may induce short-term symptomatic improvement in some cases of late-onset MADD, which may also suggest a diagnosis of an inflammatory myopathy and may result in continued administration of glucocorticoids and associated steroid side-effects [4, 50]. Our cases underline the importance of obtaining a detailed family history at the time of presentation in such cases, as well as the potential pitfalls of making a diagnosis of inflammatory myopathy on clinical grounds alone, or in the absence of conclusive muscle biopsy evidence of an inflammatory myopathy.

Our cases are the first reported from the Chaoshan region in Guangdong province, which is geographically in close proximity to Fujian and Taiwan, where the majority of c.250G > A ETFDH mutations have been reported $[15,47,48]$. A total of 52 cases with homozygous c.250G > A mutations have been reported in these regions, where the carrier frequency of c.250G $>$ A has

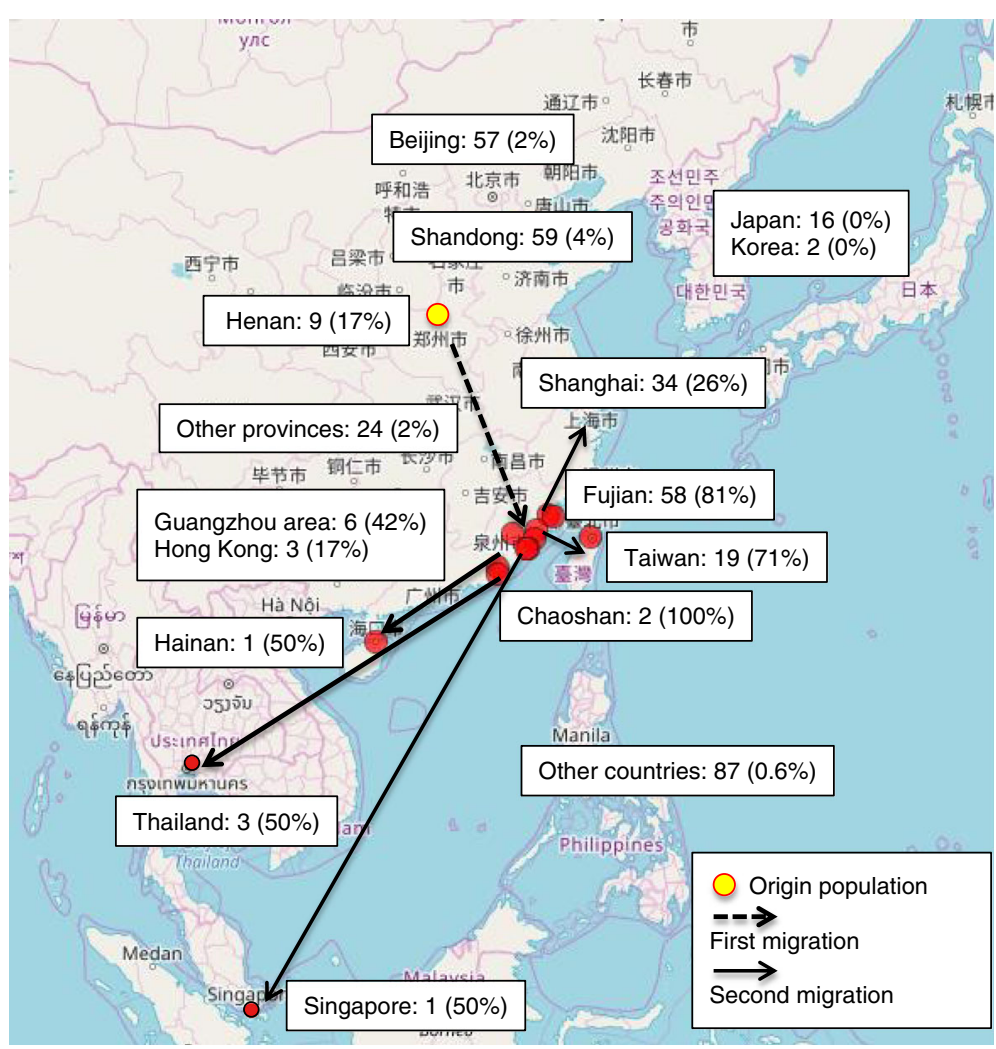

Fig. 2 Genetic epidemiology of the c.250G > A ETFDH mutation. Geographic distribution of the Southern Min population (highlighted in red); reported number of MADD case with confirmed ETFDH mutation; and the allele frequency of the c.250G > A ETFDH mutation among all reported ETFDH mutations in different regions of China and neighboring countries. The Southern Min people is believed to have migrated from middle China around Henan Province (origin) to the Southern Min region (first migration) over a thousand years ago, and further travelled to Southeast Asia and overseas in a second migration in the past centuries. Map downloaded and modified from Glottolog 4.1 edited by HMS, H\&F, R\& HPM, M/ CC BY https://glottolog.org/resource/languoid/id/minn1248.bigmap.html\#3/23.63/115.88 
Table 2 Correlation of genetic epidemiology of the ETFDH C.250G > A mutation and Southern Min Population

\begin{tabular}{|c|c|c|c|c|c|c|c|}
\hline $\begin{array}{l}\text { Regions and } \\
\text { Countries }\end{array}$ & Southern Min (\%)* & $\begin{array}{l}\text { SouthernMin } \\
\text { (millions) }\end{array}$ & $\begin{array}{l}\text { No. ETFDH } \\
\text { MADD cases }\end{array}$ & $\begin{array}{l}\text { c. } 250 G>A \\
\text { mutation }(\%)^{*}\end{array}$ & $\begin{array}{l}\text { c.250G > A } \\
\text { alleles (No.) }\end{array}$ & $\begin{array}{l}\text { Homozygous } \\
\text { cases }\end{array}$ & $\begin{array}{l}\text { Heterozygous } \\
\text { cases }\end{array}$ \\
\hline Henan & Origin & - & 9 & $17 \%$ & 3 & 0 & 3 \\
\hline Chaoshan ${ }^{1}$ & $\sim 90 \%$ & $\sim 14 \mathrm{~m}$ & 2 & $100 \%$ & 4 & 2 & 0 \\
\hline Fujian ${ }^{1,3}$ & $\sim 60 \%$ & $\sim 20 \mathrm{~m}$ & 58 & $81 \%$ & 94 & 40 & 14 \\
\hline Taiwan 2,3 & $\sim 70 \%$ & $\sim 15.6 \mathrm{~m}$ & 19 & $71 \%$ & 27 & 10 & 7 \\
\hline Hainan $n^{1,3}$ & $\sim 59 \%$ & $\sim 5 \mathrm{~m}$ & 1 & $50 \%$ & 1 & 0 & 1 \\
\hline Singapore ${ }^{2,3}$ & $\sim 37 \%$ & $\sim 1.86 \mathrm{~m}$ & 1 & $50 \%$ & 1 & 0 & 1 \\
\hline Guangzhou area ${ }^{1,3}$ & $\sim 6 \%$ & $\sim 3 \mathrm{~m}$ & 6 & $42 \%$ & 5 & 1 & 3 \\
\hline Hong Kong ${ }^{2,3}$ & $\sim 6.7 \%$ & $\sim 0.5 \mathrm{~m}$ & 3 & $17 \%$ & 1 & 0 & 1 \\
\hline Thailand ${ }^{2,3}$ & $\sim 9 \%$ & $\sim 5 \mathrm{~m}$ & 3 & $50 \%$ & 3 & 0 & 3 \\
\hline Shanghai area ${ }^{\text {a } 1,3}$ & $\sim 1 \%$ & $\sim 2 \mathrm{~m}$ & 34 & $26 \%$ & 18 & 6 & 6 \\
\hline Shandong ${ }^{a}$ & $<1 \%$ & - & 59 & $4 \%$ & 5 & 0 & 5 \\
\hline Beijing $^{a}$ & $<1 \%$ & - & 57 & $2 \%$ & 2 & 0 & 2 \\
\hline Other provinces & $<1 \%$ & - & 24 & $2 \%$ & 1 & 0 & 1 \\
\hline Japan & $<1 \%$ & - & 16 & $0 \%$ & 0 & 0 & 0 \\
\hline Korea & $<1 \%$ & - & 2 & $0 \%$ & 0 & 0 & 0 \\
\hline Other Countries ${ }^{1,2,3}$ & $<1 \%$ & $\sim 20 \mathrm{~m}$ & 87 & $0.6 \%$ & 1 & 0 & 1 \\
\hline Total & & & 381 & & 169 & 59 & 48 \\
\hline
\end{tabular}

*There is significant correlation of the estimated percentage of Southern Min population and the percentage of c.250G > A in total ETFDH mutation cases (Spearman correlation coefficient, $p<0.01$ )

c.250G > A mutation (\%): The allele frequency of the c.250G > A ETFDH mutation among all the reported cases in the regions/countries, assumed two ETFDH mutation alleles in each case

${ }^{a}$ Major Neuromuscular centres in China

Guangzhou area: including Guangzhou and surrounding cities

Shanghai area: including Shanghai and surrounding cities

$\mathrm{m}$ : millions

Estimated net number and percentage of Southern Min population in the regions calculated based on local population reports from Internet Data recourse: 1 Baidu; 2 Ethnologue; 3 Wikipedia,

been estimated to be $1.35 \%[4,15,47,51]$. People from these regions share a similar ethnic background and speak the southern Min (Min Nan) dialect. The southern Min people are believed to have migrated from middle China around Henan Province to the remote and isolated southern Min region over a thousand years ago (first migration), and further travelled to Southeast Asia and overseas in a second migration in past centuries and account for the majority of immigrant Chinese in SouthEast Asian countries. Although the previous report by $\mathrm{Xi}$ et al. suggested that the c.250G > A mutation is more common in Southern China, south of the Qin Mountains [4], the Henan province located in central China, which is historically the origin of Southern Min population has an allele frequency of $17 \%$ of c. $250 \mathrm{G}>\mathrm{A}$ mutation among 9 reported cases of MADD [6, 18, 20, 52]. In contrast, a report from Jiangxi province located in South China geographically next to Fujian found no such mutation in 13 MADD cases [38]. As shown in Fig. 2, the geographic distribution of the c.250G > A mutation is mostly consistent with the distribution and migration route of the southern Min Chinese population in China and Southeast Asia, and strongly suggests a founder effect in this population.

\section{Conclusion}

These cases emphasize the importance of considering the diagnosis of a lipid storage myopathy and RRMADD in patients presenting with muscle weakness, myalgia and exercise intolerance, and of screening for mutations in the ETFDH gene to identify patients who are responsive to riboflavin therapy. In particular, the diagnosis of RR-MADD and screening for the c.250G > A ETFDH mutation should be considered in Chinese individuals of southern Min background who present in this way, whether they are in China or have migrated to other countries.

\section{Supplementary information}

Supplementary information accompanies this paper at https://doi.org/10. 1186/s12883-019-1562-5.

Additional file 1: Table S1. 381 cases of MADD with confirmed ETFDH mutation in the literature from Pubmed and Wanfang database. 


\section{Abbreviations}

AST: Aspartate transaminase; CK: Creatine kinase; CK-MB: Creatine kinasemuscle/brain; ETFA: Electron transfer flavoprotein A; ETFB: Electron transfer flavoprotein B; ETFDH: Electron transfer flavoprotein dehydrogenase; LSM: Lipid storage myopathy; MADD: Multiple acyl-CoA dehydrogenase deficiency; MMT: Manual Muscle Testing; MRI: Magnetic resonance imaging; RRMADD: Riboflavin-responsive Multiple acyl-CoA dehydrogenase deficiency; STIR: Short time inversion recovery

\section{Acknowledgements}

Not Applicable.

\section{Authors' contributions}

WC, YQZ and YFN assessed and treated the patients and arranged muscle biopsy and genetic test. JSW and XZ reviewed literature and analysed data. JSW, WC, YQZ, XZ, SYC and FLM contributed to study design and manuscript writing. WC and YQZ contributed equally to this study. All authors have read and approved the manuscript.

\section{Funding}

No funding was obtained for this study.

\section{Availability of data and materials}

Please see supplement materials.

\section{Ethics approval and consent to participate}

This study was approved by the Ethics Committees of the Second Affiliated Hospital of Shantou University Medical College. Written informed consent was obtained from the older brother patient and patients' parent for investigations including biopsy and genetic analysis and participation of this study.

\section{Consent for publication}

Written informed consents were obtained from the older brother patient and the patients' parent for publication of this case report and any accompanying images. Copies of the written consent are available for review by the Editor of this journal.

\section{Competing interests}

The authors declare that they have no competing interests.

\section{Author details}

${ }^{1}$ Department of Neurology, The Second Affiliated Hospital of Shantou University Medical College, Shantou, Guangdong, China. ${ }^{2}$ Perron Institute for Neurological and Translational Science, QE II Medical Centre, 8 Verdun Street, Nedlands, Western Australia, Australia. ${ }^{3}$ Faculty of Health and Medical Sciences, The University of Western Australia, (M503), 35 Stirling Highway, Perth, Western Australia 6009, Australia.

Received: 26 August 2019 Accepted: 8 December 2019

Published online: 18 December 2019

\section{References}

1. Olsen RK, Olpin SE, Andresen BS, Miedzybrodzka ZH, Pourfarzam M, Merinero $B$, et al. ETFDH mutations as a major cause of riboflavin-responsive multiple acyl-CoA dehydrogenation deficiency. Brain. 2007;130(Pt 8):204554. https://doi.org/10.1093/brain/awm135.

2. Chokchaiwong S, Kuo YT, Hsu SP, Hsu YC, Lin SH, Zhong WB, et al. ETF-QO mutants uncoupled fatty acid beta-oxidation and mitochondrial bioenergetics leading to lipid pathology. Cells. 2019;8:2. https://doi.org/10. 3390/cells8020106.

3. Olsen RK, Andresen BS, Christensen E, Bross P, Skovby F, Gregersen N. Clear relationship between ETF/ETFDH genotype and phenotype in patients with multiple acyl-CoA dehydrogenation deficiency. Hum Mutat. 2003;22(1):1223. https://doi.org/10.1002/humu.10226.

4. Xi J, Wen B, Lin J, Zhu W, Luo S, Zhao C, et al. Clinical features and ETFDH mutation spectrum in a cohort of 90 Chinese patients with late-onset multiple acyl-CoA dehydrogenase deficiency. J Inherit Metab Dis. 2014;37(3): 399-404. https://doi.org/10.1007/s10545-013-9671-6.
5. Grunert SC. Clinical and genetical heterogeneity of late-onset multiple acylcoenzyme a dehydrogenase deficiency. Orphanet J Rare Dis. 2014;9:117. https://doi.org/10.1186/s13023-014-0117-5.

6. Xu HL, Lian YJ, Chen X, Zhang L, Cheng X. Two novel ETFDH mutations in a patient with lipid storage myopathy. Chin Med J. 2019. https://doi.org/10. 1097/CM9.0000000000000310.

7. Santananukarn M, Amornvit J, Pasutharnchat N, Jongpiputvanich S. Needle EMG, a jigsaw to disclose lipid storage myopathy due to multiple acyl-CoA dehydrogenase deficiency, a case report. Am J Phys Med Rehabil. 2019. https://doi.org/10.1097/PHM.0000000000001230.

8. Chen $H Z$, Jin M, Cai NQ, Lin XD, Liu XY, Xu LQ, et al. Rhabdomyolysis and respiratory insufficiency due to the common ETFDH mutation of c.250G $>$ A in two patients with late-onset multiple acyl-CoA dehydrogenase deficiency. Chin Med J (Engl). 2019;132(13):1615-8. https://doi.org/10.1097/ CM9.0000000000000288.

9. Hong D, Yu Y, Wang Y, Xu Y, Zhang J. Acute-onset multiple acyl-CoA dehydrogenase deficiency mimicking Guillain-Barre syndrome: two cases report. BMC Neurol. 2018;18(1):219. https://doi.org/10.1186/s12883-018-1221-2.

10. Wang J, Wu JC, Yu XE, Han YZ, Yang RM. Long-term outcomes of a patient with late-onset multiple acyl-CoA dehydrogenase deficiency caused by novel mutations in ETFDH: A case report. Medicine (Baltimore). 2018;97(48): e13153. https://doi.org/10.1097/MD.0000000000013153.

11. Fan X, Xie B, Zou J, Luo J, Qin Z, D'Gama AM, et al. Novel ETFDH mutations in four cases of riboflavin responsive multiple acyl-CoA dehydrogenase deficiency. Mol Genet Metab Rep. 2018;16:15-9. https://doi.org/10.1016/j. ymgmr.2018.05.007.

12. Missaglia S, Tavian D, Moro L, Angelini C. Characterization of two ETFDH mutations in a novel case of riboflavin-responsive multiple acyl-CoA dehydrogenase deficiency. Lipids Health Dis. 2018;17(1):254. https://doi.org/ 10.1186/s12944-018-0903-5.

13. Kim YJ, Ko JM, Song J, Lee KA. Clinical features of multiple acyl-CoA dehydrogenase deficiency with ETFDH variants in the first Korean cases. Ann Lab Med. 2018;38(6):616-8. https://doi.org/10.3343/alm.2018.38.6.616.

14. Gao A, Qiao LW, Duan CY, Zhao NN, Zhang W, Zhang Q. A novel mutation in the ETFDH gene of an infant with multiple acyl-CoA dehydrogenase deficiency. Zhongguo Dang Dai Er Ke Za Zhi. 2018; 20(7):529-33 (In Chinese).

15. Goh LL, Lee Y, Tan ES, Lim JSC, Lim CW, Dalan R. Patient with multiple acylCOA dehydrogenase deficiency disease and ETFDH mutations benefits from riboflavin therapy: a case report. BMC Med Genomics. 2018;11(1):37. https:// doi.org/10.1186/s12920-018-0356-8

16. Zhao YW, Liu XJ, Zhang W, Wang ZX, Yuan Y. Muscle magnetic resonance imaging for the differentiation of multiple acyl-CoA dehydrogenase deficiency and immune-mediated necrotizing myopathy. Chin Med J. 2018; 131(2):144-50. https://doi.org/10.4103/0366-6999.222323.

17. van der Westhuizen FH, Smuts I, Honey E, Louw R, Schoonen M, Jonck LM, et al. A novel mutation in ETFDH manifesting as severe neonatal-onset multiple acyl-CoA dehydrogenase deficiency. J Neurol Sci. 2018;384:121-5. https://doi.org/10.1016/j.jns.2017.11.012

18. Cui YJ, Song CL, Cheng YB. Paroxysmal muscle weakness, liver enlargement, and hypoglycemia in a boy. Zhongguo Dang Dai Er Ke Za Zhi. 2017;19(10): 1104-8 (In Chinese).

19. Xue Y, Zhou Y, Zhang K, Li L, Kayoumu A, Chen L, et al. Compound heterozygous mutations in electron transfer flavoprotein dehydrogenase identified in a young Chinese woman with late-onset glutaric aciduria type II. Lipids Health Dis. 2017;16(1):185. https://doi.org/10.1186/s12944-017-0576-5.

20. Chen M, Peng J, Wei W, Wang R, Xu H, Liu H. A novel ETFDH mutation in an adult patient with late-onset riboflavin-responsive multiple acyl-CoA dehydrogenase deficiency. Int J Neurosci. 2018;128(3):291-4. https://doi.org/ 10.1080/00207454.2017.1380641.

21. Cheng YY, Tang Y, Liu AJ, Wei L, Lin L, Zhang J, et al. Clinical features and ETFDH mutations of children with late-onset glutaric aciduria type II: a report of two cases. Zhongguo Dang Dai Er Ke Za Zhi. 2017;19(9): 975-8 (In Chinese).

22. Angelini C, Tavian D, Missaglia S. Heterogeneous phenotypes in lipid storage myopathy due to ETFDH gene mutations. JIMD Rep. 2017. https:// doi.org/10.1007/8904_2017_27.

23. Hackl A, Mehler K, Gottschalk I, Vierzig A, Eydam M, Hauke J, et al. Disorders of fatty acid oxidation and autosomal recessive polycystic kidney disease-different clinical entities and comparable perinatal renal abnormalities. Pediatr Nephrol. 2017;32(5):791-800. https://doi.org/10.1007/s00467-016-3556-5. 
24. Dai D, Wen F, Zhou S, Chen S. Clinical features and gene mutations in a patient with multiple aeyl-CoA dehydrogenase deficiency with severe fatty liver. Zhonghua Yi Xue Yi Chuan Xue Za Zhi. 2016;33(2):191-4. https://doi. org/10.3760/cma.j.issn.1003-9406.2016.02.014.

25. Fu HX, Liu XY, Wang ZQ, Jin M, Wang DN, He JJ, et al. Significant clinical heterogeneity with similar ETFDH genotype in three Chinese patients with late-onset multiple acyl-CoA dehydrogenase deficiency. Neurol Sci. 2016; 37(7):1099-105. https://doi.org/10.1007/s10072-016-2549-2.

26. Wang Z, Hong D, Zhang W, Li W, Shi X, Zhao D, et al. Severe sensory neuropathy in patients with adult-onset multiple acyl-CoA dehydrogenase deficiency. Neuromuscul Disord. 2016;26(2):170-5. https://doi.org/10.1016/j. nmd.2015.12.002.

27. Yamada K, Kobayashi H, Bo R, Takahashi T, Purevsuren J, Hasegawa Y, et al. Clinical, biochemical and molecular investigation of adult-onset glutaric acidemia type II: characteristics in comparison with pediatric cases. Brain and Development. 2016;38(3):293-301. https://doi.org/10.1016/j.braindev.2015.08.011.

28. Gregersen N, Andresen BS, Pedersen CB, Olsen RK, Corydon TJ, Bross P. Mitochondrial fatty acid oxidation defects--remaining challenges. J Inherit Metab Dis. 2008;31(5):643-57. https://doi.org/10.1007/s10545-008-0990-y.

29. Peng Y, Zhu M, Zheng J, Zhu Y, Li X, Wei C, et al. Bent spine syndrome as an initial manifestation of late-onset multiple acyl-CoA dehydrogenase deficiency: a case report and literature review. BMC Neurol. 2015;15:114. https://doi.org/10.1186/s12883-015-0380-7.

30. Zhuo Z, Jin P, Li F, Li H, Chen X, Wang H. A case of late-onset riboflavin responsive multiple acyl-CoA dehydrogenase deficiency (MADD) with a novel mutation in ETFDH gene. J Neurol Sci. 2015;353(1-2):84-6. https://doi. org/10.1016/j.jns.2015.04.011.

31. Wen B, Li D, Li W, Zhao Y, Yan C. Multiple acyl-CoA dehydrogenation deficiency as decreased acyl-carnitine profile in serum. Neurol Sci. 2015; 36(6):853-9. https://doi.org/10.1007/s10072-015-2197-y.

32. Whitaker $\mathrm{CH}$, Felice $\mathrm{K}$, Silvers D, Wu Q. Fulminant lipid storage myopathy due to multiple acyl-coenzyme a dehydrogenase deficiency. Muscle Nerve. 2015;52(2):289-93. https://doi.org/10.1002/mus.24552.

33. Shioya A, Takuma H, Yamaguchi S, Ishii A, Hiroki M, Fukuda T, et al. Amelioration of acylcarnitine profile using bezafibrate and riboflavin in a case of adult-onset glutaric acidemia type 2 with novel mutations of the electron transfer flavoprotein dehydrogenase (ETFDH) gene. J Neurol Sci. 2014;346(1-2):350-2. https://doi.org/10.1016/j.jns.2014.08.040.

34. Lu J, Ji L. Mutation analysis for a family affected with riboflavin responsivemultiple acyl-CoA dehydrogenase deficiency. Zhonghua Yi Xue Yi Chuan Xue Za Zhi. 2014;31(4):428-32. https://doi.org/10.3760/cma.j.issn.1003-9406.2014.04.004.

35. Behin A, Acquaviva-Bourdain C, Souvannanorath S, Streichenberger N, Attarian S, Bassez G, et al. Multiple acyl-CoA dehydrogenase deficiency (MADD) as a cause of late-onset treatable metabolic disease. Rev Neurol (Paris). 2016;172(3):231-41. https://doi.org/10.1016/j.neurol.2015.11.008.

36. Vieira P, Myllynen P, Perhomaa M, Tuominen H, Keski-Filppula R, Rytky S, et al. Riboflavin-responsive multiple acyl-CoA dehydrogenase deficiency associated with Hepatoencephalomyopathy and white matter signal abnormalities on brain MRI. Neuropediatrics. 2017;48(3):194-8. https://doi. org/10.1055/s-0037-1601447.

37. Yildiz Y, Talim B, Haliloglu G, Topaloglu H, Akcoren Z, Dursun A, et al. Determinants of riboflavin responsiveness in multiple acyl-CoA dehydrogenase deficiency. Pediatr Neurol. 2019. https://doi.org/10.1016/j. pediatrneurol.2019.06.015.

38. Zhu M, Zhu X, Qi X, Weijiang D, Yu Y, Wan H, et al. Riboflavin-responsive multiple acyl-CoA dehydrogenation deficiency in 13 cases, and a literature review in mainland Chinese patients. J Hum Genet. 2014;59(5):256-61. https://doi.org/10.1038/jhg.2014.10

39. Hu X, Li L, Mi R, Zhao Y, Li C. A family affected by multiple acyl-CoA dehydrogenase deficiency due to compound heterozygous mutations on ETFDH and literature review. Chin J Neonatol. 2018;33(3):205-9. https://doi. org/10.3760/cma.j.issn.2096-2932.2018.03.012.

40. Chen YLH, Yuan X, Wang X, Teng J. Clinical analysis of riboflavin-reactive lipid storage myopathy in two families. Chin J Pract Nerv Dis. 2018;21(24): 2692-6 (In Chinese).

41. Tong F, Yan R, Zhao Z. One case report of late onset riboflavin-responsive multiple acylCoA dehydrogenase deficiency. Chin J Child Health Care. 2017; 25(11):1186-8 (In Chinese).

42. Tang $Y$, Ouyang $W$, Jiang $T$, Tan $L$, Su Y. Clinical manifestation and gene analysis of multiple acyl-coa dehydrogenase deficiency with transaminase increase. Chin Pediatr Integr Tradit West Med. 2017;9(5):456-8 (In Chinese).
43. Cao JZ, Li CY, Yang J, Liang Y, Feng S, Zhang X, Li J, Zhang Y. Clinical characteristics and gene mutation analysis of riboflavin-responsive lipid storage myopathy: report of 3 cases in 2 families and review of literature. Chin J Contemp Neurol Neurosurg. 2014;14(6):479-84. https://doi.org/10. 3969/j.issn.1672-6731.2014.06.004 (In Chinese).

44. Kong LE, Zhuang SZ, Li CM, Chen LK, Zhang TT, Qiu JH, et al. Study of ETFDH gene mutations in a family with riboflavin-responsive lipid storage myopathy. J Apoplexy Nerv Dis. 2018;35(10):927-9 (In Chinese).

45. Yamada K, Ito M, Kobayashi H, Hasegawa Y, Fukuda S, Yamaguchi S, et al. Flavin adenine dinucleotide synthase deficiency due to FLAD1 mutation presenting as multiple acyl-CoA dehydrogenation deficiency-like disease: a case report. Brain and Development. 2019. https://doi.org/10.1016/j. braindev.2019.04.002.

46. Wen B, Dai T, Li W, Zhao Y, Liu S, Zhang C, et al. Riboflavin-responsive lipidstorage myopathy caused by ETFDH gene mutations. J Neurol Neurosurg Psychiatry. 2010;81(2):231-6. https://doi.org/10.1136/jnnp.2009.176404.

47. Wang ZQ, Chen XJ, Murong SX, Wang N, Wu ZY. Molecular analysis of 51 unrelated pedigrees with late-onset multiple acyl-CoA dehydrogenation deficiency (MADD) in southern China confirmed the most common ETFDH mutation and high carrier frequency of c.250G>A.J Mol Med (Berl). 2011; 89(6):569-76. https://doi.org/10.1007/s00109-011-0725-7.

48. Lan MY, Fu MH, Liu YF, Huang CC, Chang YY, Liu JS, et al. High frequency of ETFDH c.250G>A mutation in Taiwanese patients with late-onset lipid storage myopathy. Clin Genet. 2010;78(6):565-9. https://doi.org/10.1111/j. 1399-0004.2010.01421.x.

49. Law LK, Tang NL, Hui J, Fung SL, Ruiter J, Wanders RJ, et al. Novel mutations in ETFDH gene in Chinese patients with riboflavin-responsive multiple acylCoA dehydrogenase deficiency. Clin Chim Acta. 2009;404(2):95-9. https:// doi.org/10.1016/j.cca.2009.02.015.

50. Singla M, Guzman G, Griffin AJ, Bharati S. Cardiomyopathy in multiple acylCOA dehydrogenase deficiency: a clinico-pathological correlation and review of literature. Pediatr Cardiol. 2008;29(2):446-51. https://doi.org/10. 1007/s00246-007-9119-6.

51. Er TK, Liang WC, Chang JG, Jong YJ. High resolution melting analysis facilitates mutation screening of ETFDH gene: applications in riboflavinresponsive multiple acyl-CoA dehydrogenase deficiency. Clin Chim Acta. 2010;411(9-10):690-9. https://doi.org/10.1016/j.cca.2010.01.033.

52. Zhen C, Li Y, Tian F. Diagnosis and management of a twin brother and sister with Glutaric Aciduria type II. J Zhengzhou Univ (Medical Sciences). 2019;54(2):309-12 (In Chinese).

\section{Publisher's Note}

Springer Nature remains neutral with regard to jurisdictional claims in published maps and institutional affiliations.
Ready to submit your research? Choose BMC and benefit from:
- fast, convenient online submission
- thorough peer review by experienced researchers in your field
- rapid publication on acceptance
- support for research data, including large and complex data types
- gold Open Access which fosters wider collaboration and increased citations
- maximum visibility for your research: over $100 \mathrm{M}$ website views per year
At BMC, research is always in progress.
Learn more biomedcentral.com/submissions 